\title{
Tissue Levels of Clofazimine in a Case of Leprosy
}

\author{
K. V. DESIKAN AND S. BALAKRISHNAN \\ Central Leprosy Teaching and Research Institute, Chingleput 603001 , \\ India
}

\begin{abstract}
A quantitative assessment of clofazimine in some of the organs obtained at autopsy is reported. Although 40 days had elapsed since stopping treatment with the drug, significant quantities of the substance were found in the organs of the reticulo-endothelial system. The intestinal mucosa also showed a heavy concentration of the drug. Attention is drawn to the heavy accumulation of the drug during prolonged treatment.
\end{abstract}

\section{Introduction}

Clofazimine, a phenazine derivative, was synthesized in 1954 and found to have anti-tuberculosis activity (Barry et al., 1957). It was first used in the treatment of leprosy by Browne and Hogerzeil (1962). Subsequently, there have been several reports of its use in the treatment of leprosy, as well as lepra reaction. (For review see Theophilus, 1975.) A characteristic feature of this compound is that it is concentrated within the cells of the reticulo-endothelial system, being taken up by macrophages throughout the body (Conalty et al., 1971). Consequently the organs are coloured bright yellow-orange or brick-red. These changes in the organs have been studied in mice (Conalty and Jackson, 1962). The corresponding changes in human viscera have recently been described (Desikan et al., 1975). The concentration of the drug in body fluids and tissues has been estimated in experimental animals by Barry et al. (1960). Mansfield (1973) has studied the tissue concentration of clofazimine in leprosy patients at autopsy.

Recently a quantitative assessment of clofazimine in various organs obtained at autopsy has been carried out on a patient with lepromatous leprosy. The autopsy findings in this case were similar to those reported earlier (Desikan et al., 1975). The findings are presented in this communication.

\section{Materials and Methods}

The material for the present study was collected during an autopsy on a patient of lepromatous leprosy who was aged 16 years and weighed $21 \mathrm{~kg}$ at the time of the death. He had treatment with clofazimine continuously for an initial period of 6 months on a dose of $300 \mathrm{mg}$ a day. During the next 6 months, he did not 
receive the drug. Subsequently he had a second course of treatment with clofazimine for $2 \frac{1}{2}$ months on a dose of $200 \mathrm{mg}$ a day. The drug was stopped 40 days before his death. The patient also had severe diarrhoea and recurrent convulsions for which he received symptomatic treatment.

At autopsy, samples of various organs were collected for estimation of clofazimine. The method employed for the estimation of clofazimine was essentially the same as described by Barry et al. (1960) with minor modifications. About $1 \mathrm{~g}$ of the tissue was weighed and minced thoroughly to a paste with about $3 \mathrm{ml}$ of $10 \%$ acetic acid. The minced tissue was extracted with $20 \mathrm{ml}$ instalments of benzene till the benzene layer became colourless. The pooled benzene extracts were made up to a known volume with benzene. Ten $\mathrm{ml}$ of this benzene extract was treated with $1 \mathrm{ml}$ of concentrated hydrochloric acid and shaken vigorously. The layers were allowed to separate. The acid extract was removed to a graduated measuring cylinder. This acid extraction was repeated with $1 \mathrm{ml}$ instalments of concentrated acid, till no more colour was extractable. The acid extracts were pooled and made up to $10 \mathrm{ml}$ with distilled water. A stock standard solution of clofazimine containing $1 \mathrm{mg} / \mathrm{ml}$ was made with benzene as the solvent. $0.1 \mathrm{ml}$ of this stock standard was diluted to $10 \mathrm{ml}$ with benzene. This was extracted with concentrated hydrochloric acid in $1 \mathrm{ml}$ instalments till the clofazimine extraction was complete. The total volume of the pooled extract was made up to $10 \mathrm{ml}$ with distilled water. The optical densities of the standard and test solution were read in a photoelectric colorimeter using green filter $(540 \mathrm{~m} \mu)$ and the concentration of clofazimine per gram of the tissue was evaluated.

Representative samples from the organs were also processed for histological examination. For detection of clofazimine crystals, special care had to be taken in preparing the sections, since the crystals are readily dissolved in alcohol. The bits of organs were fixed in warm $10 \%$ formalin for $10 \mathrm{~min}$. Frozen sections of 10 to $12 \mu \mathrm{m}$ thickness were prepared and mounted on slides. The sections were dehydrated in the incubator for a period of 1 to $2 \mathrm{~h}$. After rapidly rinsing the sections with xylol they were mounted using Permount or any other mounting medium. The crystals could easily be recognized and the preparations made in this way were good for photography. Paraffin sections were also made for routine histological study and the sections were stained by haematoxylin eosin method and Fite-Faracco method.

\section{Results}

The colour changes in the skin were not obvious due to post-morten lividity. Subcutaneous fat and fat in the omentum were stained bright orange yellow. The loops of small intestine appeared reddish brown from the peritoneal surface. The mucosa of the intestines was stained intensely red with marked oedema and several ulcerations. The liver and spleen were reddish brown in colour on the external as well as on the cut surface. The liver was large for the size of the body and weighed $740 \mathrm{~g}$. The spleen was of normal size. The lymph nodes (both superficial and deep groups) were discrete and dark brown in colour. The mesenteric lymph nodes were stained intensely and had a bluish-brown hue. The bone marrow of the lumbar vertebrae was examined and found to be dark brown in colour. The lungs had a bright red coloration. The skeletal muscles showed a brick-red colour. 
Apart from the colour changes, the other gross post-mortem findings were the extensive pleural adhesions, multiple sub-diaphragmatic abscesses and the occurrence of a circumscribed area of caseation in the brain measuring $2.5 \times 1.5 \times 0.5 \mathrm{~cm}$ in the left cerebral hemisphere adjacent to falx cerebri.

The levels of clofazimine in various organs are given in Table 1.

TABLE 1

\begin{tabular}{llc}
\hline Serial No. & Organ $(\mathrm{g})$ & Concentration $(\mathrm{mg} / \mathrm{g})$ \\
\hline 1 & Liver (740) & 0.18 \\
2 & Spleen (60) & 1.00 \\
3 & Small Intestine & 2.10 \\
4 & Lungs: Right (330) & 0.17 \\
& Left (260) \\
5 & Kidney: Right (60) & 0.04 \\
6 & Left (60) & 0.35 \\
7 & Omentum & 3.30 \\
8 & Lymph nodes (mesenteric) & Not detected \\
\hline
\end{tabular}

It could be seen that clofazimine was found in all organs studied except the brain. High concentrations were noticed in the mesenteric lymph nodes, small intestine and spleen. A relatively smaller concentration of the drug was found in the omentum, liver and lungs. The kidney showed only traces.

Histological examination of the frozen section of the small intestine showed a heavy deposit of the crystals in the mucosa (Fig. 1). Large clumps of the crystals were seen in the liver also (Fig. 2) but it was difficult to define the exact location of these crystals. In the lymph nodes, the crystals were densely packed in the macrophages (Fig. 3). A relatively smaller amount was found in the spleen and lungs and appeared to be located in the macrophages. Frozen unstained sections of kidney, adrenals, testes, heart, aorta, pancreas and thyroid did not reveal any crystals. Histological examination of the paraffin sections confirmed the lesion in the brain to be a tuberculoma. The subdiaphragmatic abscesses were also tuberculous and the smears made from the pus showed acid-fast bacilli. There was massive fatty infiltration of the liver with scattered lepromatous leprosy lesions in the parenchyma. Yellowish-brown pigments were seen in the liver cells. The pigments were also seen in macrophages in the spleen, lungs and lymph nodes. These could possibly be due to clofazimine after partial dissolution during processing the tissues. Clumps of dark brown material were also seen within the blood vessels of several organs. The intestinal mucosa showed "ghosts" of clofazimine crystals. There was ulceration and marked infiltration of all the layers with mononuclear cells. The inflammatory exudation and ulceration is most likely due to accumulation of clofazimine crystals in the intestinal mucosa.

\section{Discussion}

A gross examination of the organs at autopsy showed that in addition to fat in all the locations, the liver, spleen, lymph nodes, bone marrow and lungs had taken 


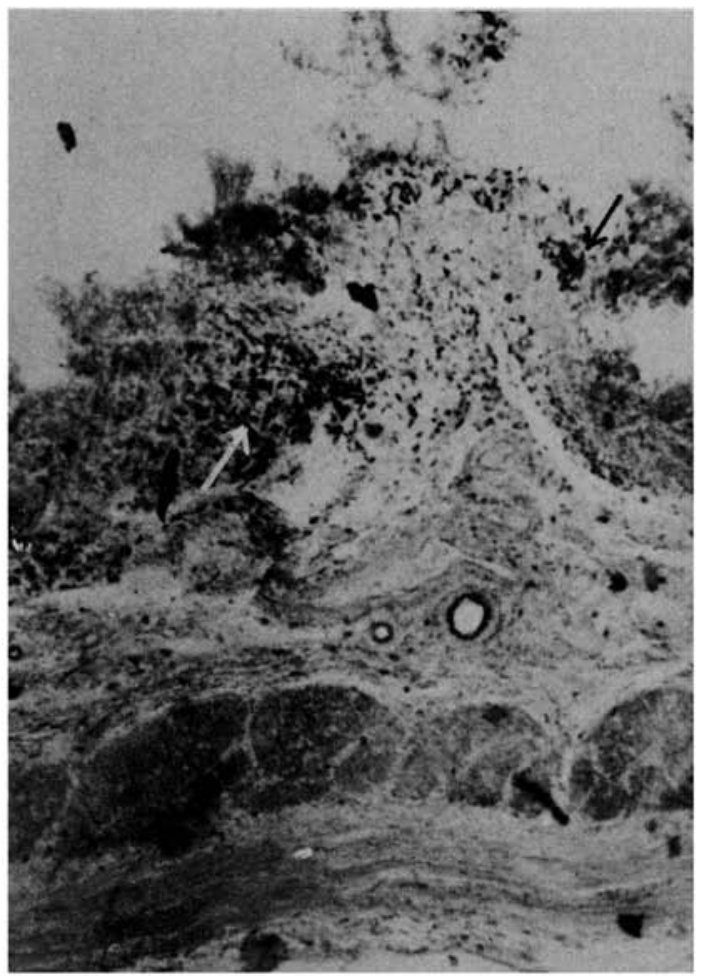

Fig. 1. Frozen section of small intestine. The arrows indicate a heavy deposit of clofazimine in the mucosa. $(\times 42)$.

up the colour of the drug. Frozen sections of liver, spleen, ly mph nodes and lungs showed clofazimine crystals mainly within the macrophages. The omentum showed the dye as droplets rather than as crystals, since clofazimine is a fat soluble substance. On a quantitative estimation, the drug was found to be concentrated to a significantly high level in all these organs. The lymph nodes from the mesentery contained the maximum concentration of $3.3 \mathrm{mg} / \mathrm{g}$ of the tissue. In other words, the drug had accumulated in the lymph node, constituting as much as $0.33 \%$ of the weight of the organ. Judging from the depth of the coloration, the concentration of the drug could not have been high in other groups of lymph nodes. Of the other organs of the reticulo-endothelial system studied, the spleen contained the next highest concentration, the drug forming $0.1 \%$ of the weight of the organ. Liver and lungs were next in order, the concentration nearing $0.02 \%$. The concentration of the dye substance in the macrophages of these organs is consistent with the finding in mice by Conalty and Jackson (1962), who have shown that clofazimine is taken up by reticulo-endothelial cells. The lungs, which contain a large number of macrophages, also contain the drug in these cells. The 


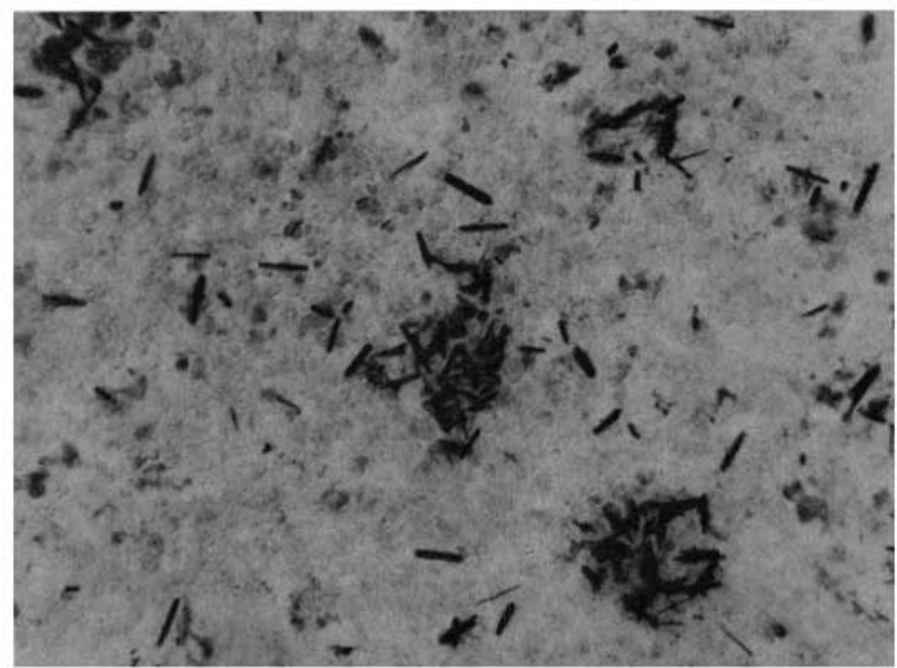

Fig. 2. Photomicrograph showing clofazimine crystals in liver. $(\times 120)$.

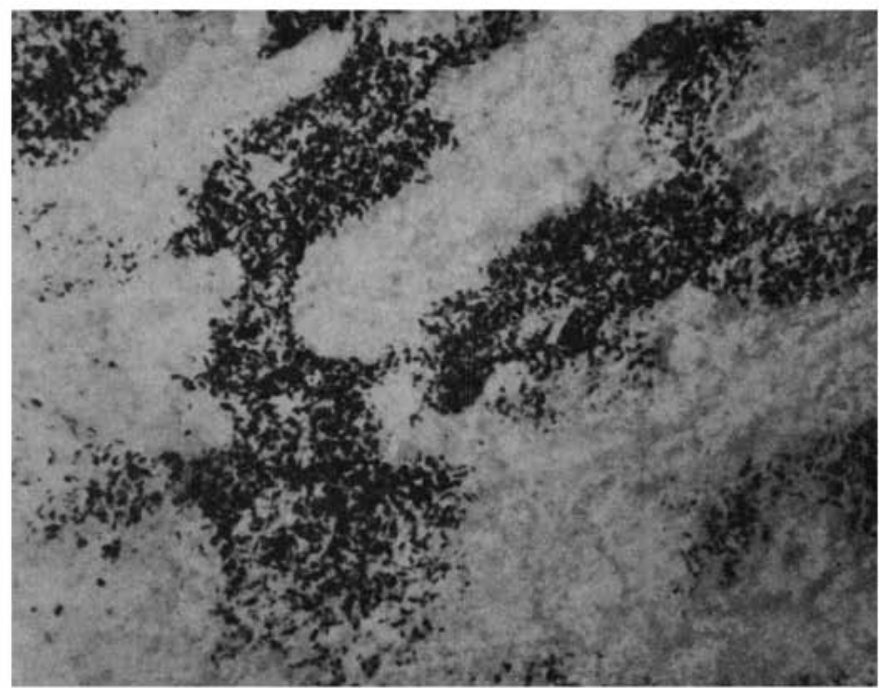

Fig. 3. Frozen section through a mesenteric lymph node showing massive deposits of clofazimine. $(\times 42)$. 
very low concentration of the drug in the kidney $(0.04 \mathrm{mg} / \mathrm{g})$ indicates that the accumulation of the drug is proportional to the number of macrophages that the organ or tissue contains. This could be the reason for the drug becoming concentrated heavily at the sites of the leprosy lesions in the skin, which are composed mainly of macrophages.

The heavy concentration of the drug in the intestinal mucosa is of special note. The drug is absorbed through the intestines and therefore is accumulated in the mucosa. Such an accumulation in the intestinal mucosa would cause diarrhoea which is commonly associated with clofazimine therapy (Desikan et al., 1975). The case presented here also had severe diarrhoea.

Although the concentration of the drug per gram of tissue is less in liver compared to lymph nodes and spleen, it must be realized that the total quantity of the substance in the liver is quite high, in view of its size. In the case reported, the total amount of the drug in the liver works out to $133.2 \mathrm{mg}$ since the organ weighed $740 \mathrm{~g}$. It could be presumed that the drug was uniformly distributed in the organ because the cut surface showed uniform coloration. The corresponding total amount in spleen (which was also uniformly stained and weighed $60 \mathrm{~g}$ ) was only $60 \mathrm{mg}$. Although the concentration of the drug in the mesenteric lymph nodes was very high, the drug was not uniformly distributed in all the lymph nodes, so that the total amount of the dye in the lymphoid tissues of the body taken as a whole would have been less than the amount in the liver.

In the present study, the organs listed in the table were selected for quantitative assessment of clofazimine, because these organs showed distinct coloration due to the drug. The quantities of clofazimine estimated chemically roughly corresponded with the intensity of coloration as judged by gross examination of the organ. The brain had not taken up any colour nor were any crystals seen in the frozen sections. Even so, the tissue was processed chemically to detect the presence of the drug and to check whether the dye could pass the blood-brain barrier. Such a possibility has been ruled out by the absence of the dye in the brain. The peripheral nerves were not examined for the presence of the drug in this case.

The present study provides some idea of the quantity of the drug that could accumulate in human tissues during regular treatment with clofazimine. It has been shown that in liver alone as much as $133 \mathrm{mg}$ of the drug had accumulated in the course of $81 / 2$ months of interrupted treatment with clofazimine. Taking into account that the patient weighed only $21 \mathrm{~kg}$ the amount of the drug in the liver appears substantial. Further, it has been mentioned that the adipose tissue all over the body also contained the drug. The drug was also present in the bone marrow and to a lesser extent in the skeletal muscles as judged by the coloration of the organs. Since this was a case of lepromatous leprosy, the drug could presumably be distributed throughout the skin. All this added up would constitute a sizeable amount of the drug in the body. The implications of such an accumulation of the drug, particularly in organs like liver and small intestine, are not clear at the moment, but this fact has to be borne in mind when a patient is subjected to prolonged treatment with clofazimine. 


\section{Acknowledgement}

Clofazimine therapy of the patient was under the supervision of Dr K. Ramanujam and Dr G. Ramu who have kindly supplied the clinical details. Technical assistance provided by Sri P. B. Nath in preparation of tissue sections and by Sri C. Samuel in photography is acknowledged as also is the secretarial help of Sri M. Nagarethinam.

\section{References}

Barry, V. C., Belton, J. G., Conalty, M. S., Denney, J. M., Edward, D. W., O’Sullivan, J. F., Twomey, D. and Winder, F. (1957). A new series of phenazine (rimino-compounds) with high antituberculosis activity. Nature, Lond. 179, 1013.

Barry, V. C., Buggle, K., Byrne, J., Conalty, M. L. and Winder, F. (1960). Absorption, distribution and retention of riminocompounds in the experimental animal. Ir. J. med. Sci. 416, 345 .

Browne, S. G. and Hogerzeil, L. M. (1962). "B663" in the treatment of leprosy; preliminary report of a pilot trial. Lepr. Rev. 33, 6 .

Conalty, M. L., Barry, V. C. and Jina, A. (1971). The anti-leprosy agent B663 (Clofazimine) and the reticulo-endothelial system. Int. J. Lep. 39, 479.

Conalty, M. L. and Jackson R. D. (1962). Uptake by reticulo-endothelial cells of the Reminophenazine B663. Br.J. exp. Path. 43, 650.

Desikan, K. V., Ramanujam, K., Ramu, G. and Balakrishnan, S. (1975). Autopsy findings in a case of lepromatous leprosy treated with clofazimine. Lepr. Rev. 46, 181.

Mansfield, E. (1973). Systemic tissue concentrations of B 663 in leprosy patients. Abstracts of papers, Tenth International Leprosy Congress, Bergen, p.10.

Theophilus, S. (1975). Clinical observation with clofazimine in the treatment of leprosy. Lepr. India 47, 267. 